\title{
Radioecological sensitivity of the shallow marine environment
}

\author{
M. Iosjpe \\ Norwegian Radiation Protection Authority, Grini næringspark 13, 1332 Østerås, Norway
}

\begin{abstract}
An evaluation of the radioecological sensitivity of the coastal marine regions can be used to improve risk management and decision-making systems, especially the development of response strategies, by defining the most sensitive areas. Environmental sensitivity analysis has been carried out for six marine coastal regions for a single deposition of $1000 \mathrm{~Bq} / \mathrm{m}^{2}$ for radionuclides ${ }^{137} \mathrm{Cs},{ }^{90} \mathrm{Sr},{ }^{131} \mathrm{I}$ and ${ }^{239} \mathrm{Pu}$. The analysis has been based on dose calculations during the 1 st year, 2 nd year and $10^{\text {th }}$ year after releases of radionuclides for adults and children of 1 and 10 years of age. The calculations have been carried out by the compartment model, which includes the processes of dispersion of radioactivity in water - sediment environment and accumulation of radionuclides by marine organisms. Doses to man are calculated on the basis of seafood consumption. Results show that for all regions the radiation doses for adults are significantly higher than doses calculated for children. Further, the doses calculated for the first year dominate the doses of the second and tenth year following the releases of radionuclides. Calculations also indicate that doses vary greatly for different radionuclides; and the dose levels for the same radionuclide vary greatly in different marine environments.
\end{abstract}

\section{MODELLING APPROACH}

An evaluation of the radioecological sensitivity of the coastal marine regions can be used to improve risk management and decision-making systems, especially the development of response strategies, by defining the most sensitive areas. Modelling of the radioecological sensitivity after the release of radionuclides into the marine environment has to include different aspects: (i) dispersion of radionuclides in water and sediment phases, (ii) bioaccumulation of radionuclides in biota and (iii) dose assessments.

The present results correspond to a release scenario, which has been developed under the course of the EMRAS II program [1], where a single deposition of $1000 \mathrm{~Bq} / \mathrm{m}^{2}$ of radionuclides ${ }^{137} \mathrm{Cs},{ }^{90} \mathrm{Sr},{ }^{131} \mathrm{I}$ and ${ }^{239} \mathrm{Pu}$ is released into all marine regions. The radionuclide concentrations have been calculated for seawater (filtered and unfiltered), fish, molluscs, crustaceans and seaweeds; the radiation doses, during the 1 st year, 2nd year and 10th year after releases of radionuclides, have been calculated for adults and children of 1 and 10 years of age.

The calculations have been carried out on the basis of the NRPA compartment model [2, 3]. The compartment structures for surface, mid-depth and deep water layers have been developed based on the description of polar, Atlantic and deep waters in the Arctic Ocean and the Northern Seas and sitespecific information for the compartments (a part of the surface compartment is shown in Figure 1). The model includes the processes of advection of radioactivity between water compartments, sedimentation, diffusion of radioactivity through pore water in sediments, resuspension, particle mixing including mixing due to bioturbation and a burial process of radioactivity in deep sediment layers. Radioactive decay is calculated for all compartments. The contamination of marine organisms is further calculated from the radionuclide concentrations in filtered seawater in the different water regions. Doses to man are calculated on the basis of seafood consumption. It is important to note that external doses to man have not been calculated in the present paper because comparison of the contribution to individual dose rates 
Table 1. Sediment distribution coefficients $\left(\mathrm{m}^{3} / \mathrm{t}\right)$ and concentration factors for biota $\left(\mathrm{m}^{3} / \mathrm{t}\right)$.

\begin{tabular}{lcccc}
\hline & ${ }^{137} \mathrm{Cs}$ & ${ }^{90} \mathrm{Sr}$ & ${ }^{131} \mathrm{I}$ & ${ }^{239} \mathrm{Pu}$ \\
\hline Sediment distribution coefficients & 4000 & 8 & 70 & 100000 \\
Concentration factors for fish & 100 & 3 & 9 & 100 \\
Concentration factors for crustaceans & 50 & 5 & 3 & 200 \\
Concentration factors for molluscs & 60 & 10 & 10 & 3000 \\
Concentration factors for seaweeds & 50 & 10 & 10000 & 4000
\end{tabular}

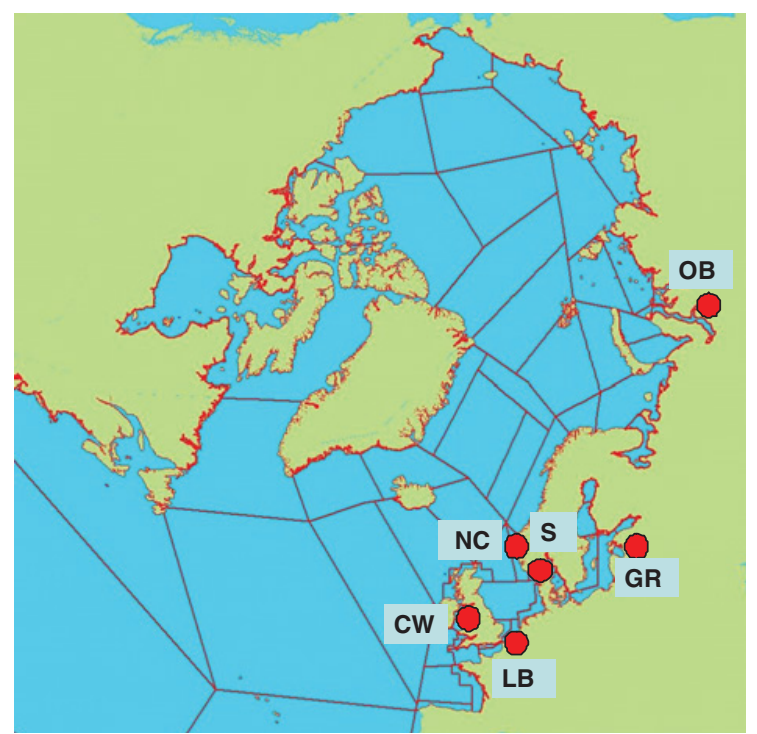

Figure 1. The surface structure of the NRPA box model and location of the selected marine regions.

from seafood ingestion and external exposure indicates a clear domination of the ingestion pathway for marine environment [4-6].

\subsection{Selected radionuclides}

Table 1 shows that the values of the sediment distribution coefficients and concentration factors for biota vary greatly for selected radionuclides in the marine environment. It is necessary to note that sediment distribution coefficient is one of the key parameters describing water-sediment interactions, while concentration factors describe the process of radionuclide bioaccumulation by marine organisms [7].

\subsection{Selected marine regions}

Calculations were carried out for six shallow marine coastal environments: Cumbrian waters of the Irish Sea (CW), Lyme Bay on the English Channel (LB), North Sea of the Norwegian coasts (NC), Skagerrak (S), the Gulf of Riga on the Baltic Sea (GR), and Ob Bay on the Kara Sea (OB). The selected marine regions are shown in Figure 1. 

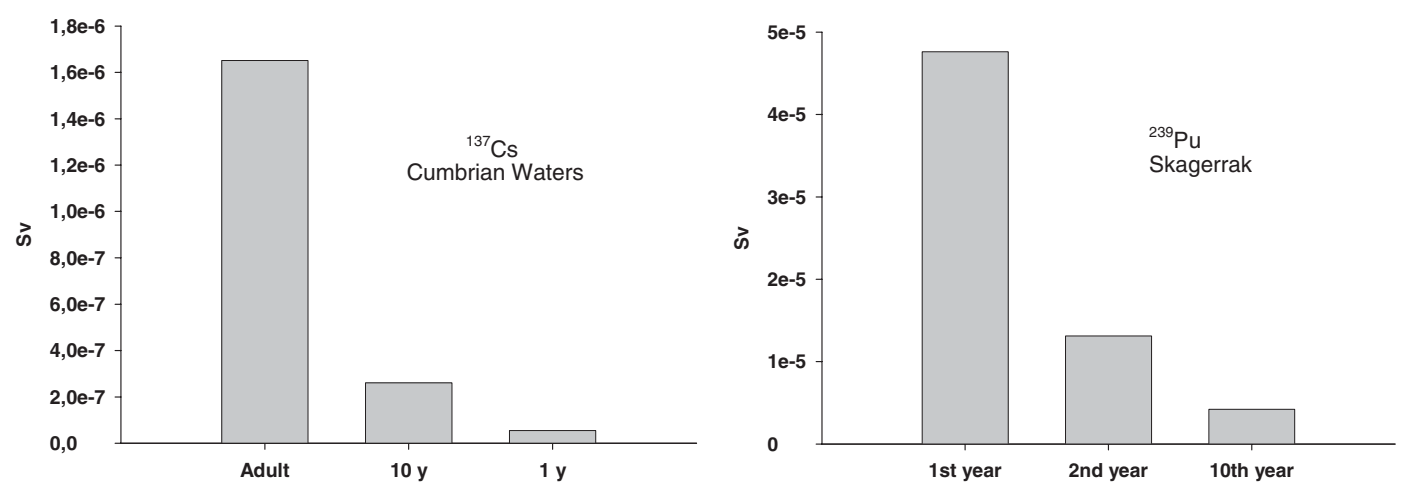

Figure 2. Dose (Sv) for different age from ${ }^{137} \mathrm{Cs}$ (Cumbrian Waters), and during different times from ${ }^{239} \mathrm{Pu}$ for adult (Skagerrak).

\section{RESULTS AND DISCUSSION}

Results of the calculations show that for all regions the radiation doses for adults are significantly higher than doses calculated to children of 1 and 10 years of age. This is primarily due to low seafood consumption of children, which turns out to be a more important factor than the increase of dose conversion factors for children. Further, the doses calculated for the first year dominate the doses of the second and tenth year after the release of radionuclides. This is true for all selected regions. These results could be explained by redistribution of radionuclides with time between surface water and deep water compartments, as well as the sedimentation and burial processes. Typical results for the dose distributions of ${ }^{137} \mathrm{Cs}$ and ${ }^{239} \mathrm{Pu}$ for different ages and during different times are shown in Figure 2.

Therefore, the calculation of the doses to adults during the first year after radionuclide deposition is the most interesting for this modelling. Figure 3 shows doses to adults for the four radionuclides ${ }^{131} \mathrm{I},{ }^{137} \mathrm{Cs},{ }^{90} \mathrm{Sr}$, and ${ }^{239} \mathrm{Pu}$ from different types of seafood for the Cumbrian Waters. The doses were calculated for the first year after deposition. Sea food consumption corresponds to the results published in [8] for the population of the coastal regions. For the present calculations it is used following consumption for adult: $51,17,14$, and $5 \mathrm{~kg} / \mathrm{y}$ for fish, crustaceans, molluscs and seaweeds, respectively. Figure 3 clearly indicates that dose from ${ }^{131} \mathrm{I}$ is strongly dominated by seaweed consumption ( $98 \%$ of the total dose), fish and molluses consumption significantly dominate doses from ${ }^{137} \mathrm{Cs}$ and ${ }^{239} \mathrm{Pu}(72 \%$ and $59 \%$ of the total doses, respectively). A dose from ${ }^{90} \mathrm{Sr}$ is dominated by fish and molluscs consumption (68\% of the total dose), while doses from fish and molluscs are approximately equal.

Results of simular dose calculations for all coastal environments are shown in Figure 4. Results show the differences of radioecological sensitivity between different marine regions for different radionuclides and points of interest. The highest doses were found for the Ob Bay location for ${ }^{131} \mathrm{I},{ }^{137} \mathrm{Cs}$ and ${ }^{90} \mathrm{Sr}$, while the highest dose for ${ }^{239} \mathrm{Pu}$ is found for the Gulf of Riga. It is important to note that the assumed level of seafood consumption has been the same for all coastal environments. It is obvious that doses for each marine region in Figure 4 are strongly dependant on radionuclide speciation. For example, the region distribution of the ${ }^{239} \mathrm{Pu}$ doses in Figure 4 differs significantly from other radionuclides. Further, the doses for the same radionuclide vary greatly in different marine environments. Such differences could be explained by the complexity of the processes of radionuclide dispersion and bioaccumulation, which can progress differently in different marine locations. Therefore, it could be interesting to define and analyze which model parameters play a key role in the evaluation of environmental sensitivity. It could also be interesting to analyze other end points of an environmental sensitivity analysis, for example nonhuman dose analysis [9]. 

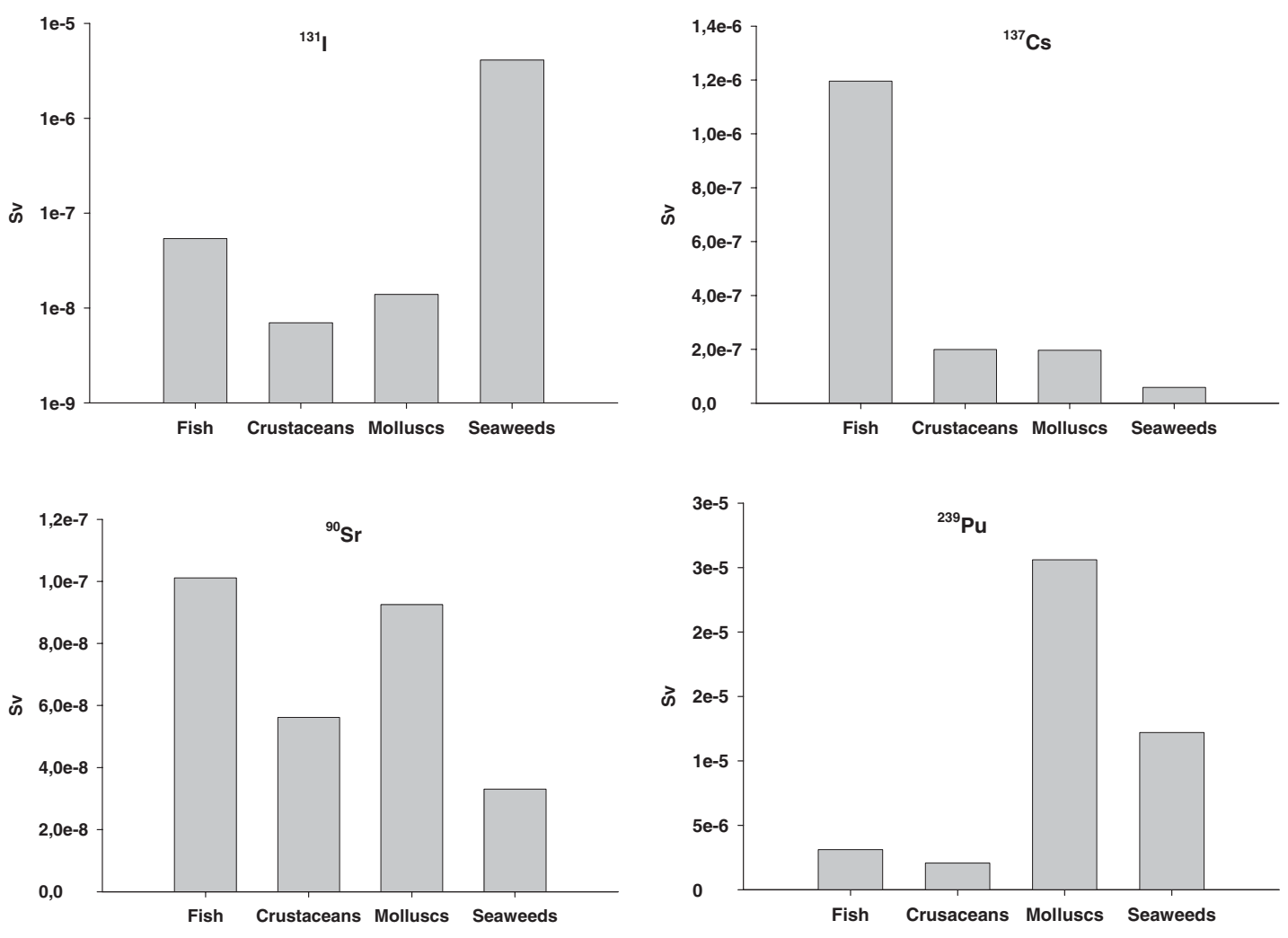

Figure 3. Doses (Sv) from one year of consumption of ${ }^{131} \mathrm{I},{ }^{137} \mathrm{Cs},{ }^{90} \mathrm{Sr}$, and ${ }^{239} \mathrm{Pu}$ in fish, crustaceans, molluscs, and seaweed.
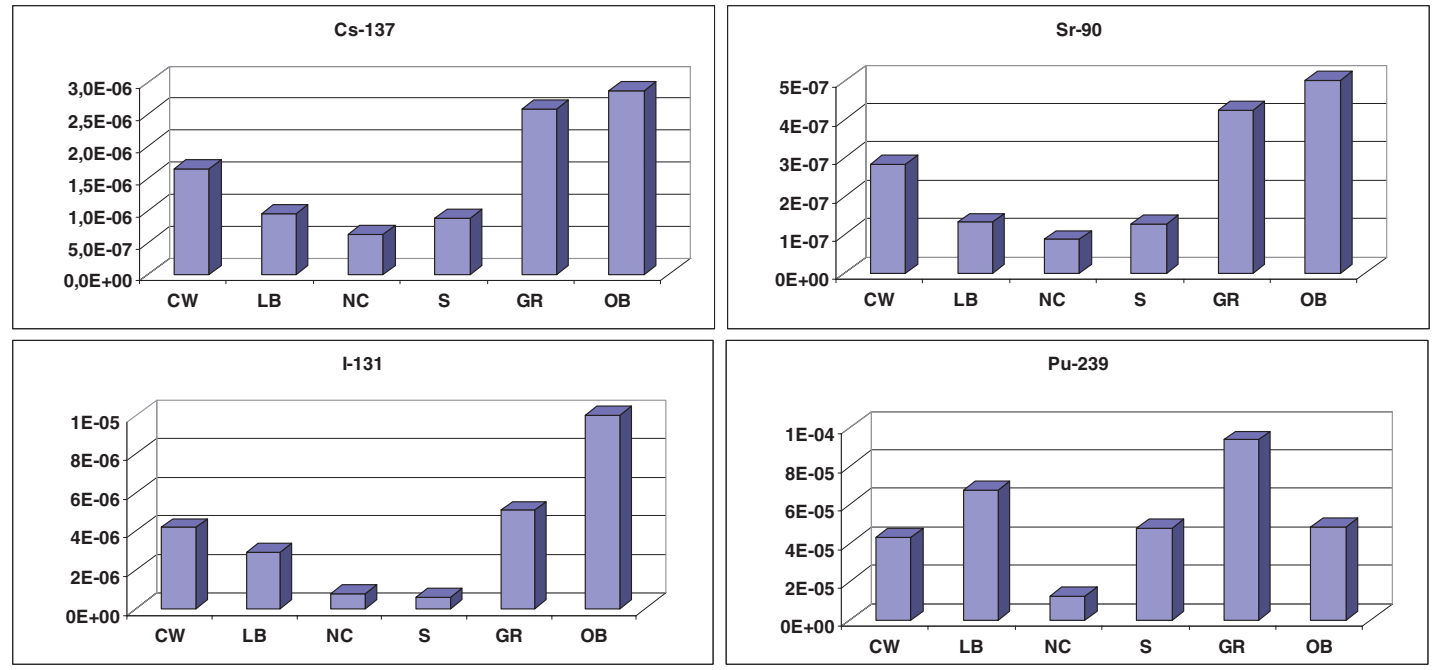

Figure 4. Doses in Sv from one year of the same consumption of I-131, Cs-137, Sr-90, and Pu-239 in seafood for locations: Cumbrian waters (CW), Lyme Bay (LB), Norwegian coastal current (NC), Skagerrak (S), the Gulf of Riga (GR) and $\mathrm{Ob}$ Bay $(\mathrm{OB})$. 


\section{CONCLUSION}

Environmental sensitivity analysis has been carried out for six marine coastal regions for a single deposition of $1000 \mathrm{~Bq} / \mathrm{m}^{2}$ for radionuclides ${ }^{137} \mathrm{Cs},{ }^{90} \mathrm{Sr},{ }^{131} \mathrm{I}$ and ${ }^{239} \mathrm{Pu}$. Analysis has been based on dose calculations during the 1 st year, 2 nd year and $10^{\text {th }}$ year after releases of radionuclides for adults and children of 1 and 10 years of age.

Results show that for all regions the radiation doses for adults are significantly higher than doses calculated for children. Further, the doses calculated for the first year dominate the doses of the second and tenth year following the releases of radionuclides. Calculations also indicate that doses vary greatly for different radionuclides; and the dose levels for the same radionuclide vary greatly in different marine environments.

Environmental sensitivity analysis could potentially be improved by the definition and analysis of the model parameters which play a key role in the processes of radionuclide distribution and bioaccumulation. An analysis of end points other than doses to man could also be interesting in evaluating the environmental sensitivity of coastal marine regions.

\section{Acknowledgments}

The author wishes to thank Dr. Bliss L. Tracy, Dr. Luigi Monte, Prof. Franca Carini and Dr. John E. Brittain (the EMRAS II programme, Sensitivity Environment Group) for their participation in constructive discussions.

\section{References}

[1] EMRAS II, Working group 8. Environmental sensitivity: Documents. http://www-ns.iaea.org/projects/emras/emras2/working-groups/working-group-eight.asp?s=8

[2] Iosjpe M., Radioactivity in the Environment, 8, 2006, 463-476.

[3] Iosjpe M., Brown J. and Strand P., J. Environ. Radioact., 2002, 60, 91-103.

[4] The radiological exposure of the population of the European Community from radioactivity in the Mediterranean Sea. Project “MARINA-Med”. EC, Radiation Protection Series 69, XI-094/93, 1994.

[5] Modelling of the radiological impact of radioactive waste dumping in the Arctic Seas. IAEATECDOC-1330, 2003.

[6] Iosjpe M., Reistad O. and Amundsen I., J. Environ. Radioact., 2009, 100, 184-191.

[7] IAEA Technical Reports Series No. 422, IAEA, Vienna, 2004.

[8] Smith, K. and Jones, A., Generalised habit data for radiological assessment, NRPB Report W41, 2003.

[9] Iosjpe M. and A. Liland, in Book of abstracts, on the International Conference on Environmental Radioactivity - New Frontiers and Developments, Rome, 2010, pp. 59-60,

http://www.environmentalradioactivity2010.com/. 